\title{
INFECTION OF PROTOZOAN AND HELMINTH PARASITES AMONG THE OUT-PATIENTS OF DHAKA MEDICAL COLLEGE HOSPITAL
}

\author{
Hamida Khanum*, Ainun Nahar, Mt. Tahmina Karim and Hasina Banu \\ Department of Zoology, University of Dhaka, Dhaka 1000, Bangladesh
}

\begin{abstract}
The intestinal parasites and their prevalence and intensity of infestation was investigated. A total of 793 stool samples were examined from the out patients of Dhaka medical College Hospital. Eggs and lavae of six species of intestinal parasites were recovered, of which two species were protozoans: Entamoeba histolytica Schaudinn, 1903; and Giardia intestinalis (Lambl, 1859) and four species of helminthes: Ascaris lumbricoides Linnaeus, 1758; Trichuris trichiura (Linnaeus, 1771) Stiles, 1901; Ancylostoma duodenale (Dubini, 1843) Creplin, 1845; and Enterobius vermicularis (Linnaeus, 1758)]. The overall prevalence of infestation was $43.253 \%$ and egg per gram (EPG) of infestation was slightly higher in males than females. Prevalence of intestinal helminth was found higher than intestinal protozoans. Among the six species of intestinal parasites, Ascaris lumbricoides showed highest prevalence (21.689\%) and Enterobius vermicularis lowest prevalence (1.008\%). Among the patients of the hospital, highest prevalence $(83.333 \%)$ was observed in 0 - 10 years age group and lowest $(30.167 \%)$ in $51-60$ years age-group.
\end{abstract}

Key words: Out-patients, intestinal parasites, prevalence, intensity

\section{INTRODUCTION}

Parasites present continual and unacceptable threat to the well-being of millions of people and to domesticate animals in all parts of the world and the cost of parasites in terms of human misery and economic loss is incalculable. The poorest people in the world suffer the greatest burden of infection is beyond doubt. It increases disease productivity, which is associated with intestinal parasite burdens (Gilgen et al. 2001). World Health Organization (WHO 1987) reported that in 1987 there were about 480 million people infected with $E$. histolytica and 30 million developed invasive forms of amoebiasis of these at least 40,000 died consequently mainly due to fulminating colitis or liver abscess. Amoebiasis is a significant world-wide health problem, especially in developing countries. It is presently one of the third most common causes of death by parasitic diseases. Infection by E. histolytica is ubiquitous and about 500 million people each year have amoebiasis of which only 10 experience symptomatic disease (Walsh 1986, WHO 1997).

Diarrhoea is a major public health problem world-wide, especially in children. One in ten child deaths result globally from diarrhoeal disease before

*Corresponding author: hamida_khanum@yahoo.com

(C) 2016 Zoological Society of Bangladesh DOI: 10.3329/bjz.v44i1.30179 
their fifth birthday, resulting in about 800000 fatalities worldwide annually, most occurring in sub-Saharan Africa and south Asia (Liu et al. 2010, WHO 2005)). In south Asia, diarrhoea accounts for $26.1 \%$ of childhood deaths with a peak incidence in their early years of Life (Walker et al. 2012).

Giardia is endemic in Bangladesh and the reported prevalence of infection ranges from 4 to $21 \%$ with dearrhoea (Alam and Khanum 2005, Khanum et al. 1998). The prevalence of giardiasis was higher among the children between the ages of 5 and 15 years. Children at young ages are the most vulnerable for parasitic infections and tended to have higher intensity compared to any other age group (Anderson 1986, Khanum et al. 1999). Male children are more susceptible than female because of their staying habit from outside the house (Stephenson 1987).

Shakur and Ehsan (1993) investigated the intestinal parasites of children aged between 0 and 5 years in Dhaka Shishu Hospital. Their study showed Giardia intestinalis in $21 \%$. Giardia was the first of these organisms to be associated with human disease, and there have been many documented cases of water borne giardiasis since 1970s. Khanum et al. (2001) reported highest incidence of ascariasis, trichuriasis and hookworms between the age group of 11 and 20 years. The prevalence of ascariasis and trichuriasis decline with age whereas, ancylostomiasis increases with age (Saha and Chowdhury 1981). As man is the only reservoir of the helminthiasis in most of the cases, so infected people should be treated with anti-helminthies (Khanum et al. 1997).

Khanum et al. (2005) carried out a study on the children of 2 and 12 years old in two different rural areas (Gazirchat, Savar, Dhaka and Kutumbopur, Comilla) in Bangladesh and found higher prevalence in males than females in both the study areas and hookworm infection was the highest among the age group of $6.1-8(34.28 \%)$ in both the areas.

The objective of the present study was to determine the prevalence and intensity of intestinal protozoan and helminth parasites among the male and female out-patients (1 - 60 years) of Dhaka Medical Collage Hospital.

\section{MATERIAL AND METHODS}

A total of 793 stool specimens were collected from Dhaka Medical College Hospital. The patients were from 1- 60 years of age. The patients were divided into 6 age groups: 0 - 10, $11-20,21-30,31-40,41-50$ and 51 - 60 years. This study was a cross sectional type of study to find the prevalence of intestinal parasites among the out patients conducted by interviewing to ascertain their perception and habit with regard to protozoan and helminth infections in the patients. The survey covered the period from November 2007 to October 2008. 
The faecal specimens were received in the morning between 8 a.m. and 12.30 p.m. and examined on the day of collection. Before macroscopic examination of stool samples information regarding age and sex were recorded. At first the stool was examined with naked eye. The formol-ether technique was performed according to the method described by Cheesbrough (1987). The sample $(1 \mathrm{~g})$ was placed in a test tube and $5 \mathrm{ml}$ of normal saline was added and it was then centrifuged at $3000 \mathrm{rpm}$ for $3 \mathrm{~min}$ and supernatant was discarded. The process was repeated until the supernatant was clear. The sediment was examined using $10 \mathrm{X}$ objective with the condenser. The $40 \mathrm{X}$ objective was used to identify the small cysts and eggs. Data generated was analyzed by the SPSS Software-15 for mean analysis, correlation and Chi-square tests.

\section{RESULTS AND DISCUSSION}

A total of 793 human stool samples were examined in Dhaka Medical College Hospital for gastrointestinal parasites, of which eggs and larvae of six species of gastrointestinal parasites including the protozoans and helminthes were found. Of the six species two were protozoans (Entamoeba histolytica and Giardia intestinalis) and four were helminth (Ascaris lumbricoides, Trichuris trichiura, Ancylostoma duodenale and Enterobius vermicularis). During the study period, the overall prevalence of infection was $43.253 \%$ in the patients of Dhaka Medical College Hospital. Among the patients, the prevalence was higher in female $(46.732 \%)$ than in males $(41.067 \%)$ (Table 1$)$.

Table 1. Prevalence and EPG of intestinal parasites in male and female separately

\begin{tabular}{lllllll}
\hline Patients of & Male & 487 & 200 & 41.067 & 293 & 1.465 \\
\cline { 2 - 4 } & Female & 306 & 143 & 46.732 & 202 & 1.412 \\
& Combined & 793 & 343 & 43.253 & 495 & 1.443 \\
\hline
\end{tabular}

Khanum et al. (2005) carried out a study on the children of 2 - 12 years old in two different rural areas (Gazirchat, Savar, Dhaka and Kutumbopur, Comilla) of Bangladesh. The prevalence was higher in males than females in both the study areas and hookworm infection was the highest among the age group of 6.1 - 8(34.28\%) in both the areas. Muttalib et al. (1976) reported Entamoeba histolytica, Entamoeba coli, Giardia, Ascaris, hookworm, Trichuris, Fasciola buski, Strongyloides, Hymenolepis nana and Oxyuris vermicularis from rural children of Bangladesh. Chowdhury (1978) investigated intestinal parasitic infections in the populations of Dhaka and reported eight species of parasites. Khaled (1983) found eight species of intestinal parasites in members of Bangladesh rifles, and Islam et al. (1983) recorded five species of nematodes from the patients of Barisal Medical College and Hospital. 
In $\mathrm{DMCH}$ most of the patients are from old Dhaka and from slum areas where hygienic conditions are very poor. Muttalib et al. (1976) reported higher prevalence $(57.77 \%)$ of infection in boys than in girls $(42.23 \%)$. Comparatively high prevalence of infestation was reported by Khanum and Alam (2005). The probable causes of higher prevalence of infection in females may be due to low immunity, repeated pregnancies, lack of health education and malnutrition. In the present investigation, the overall prevalence $(30.264 \%)$ of helminthes was found higher than the protozoans $(12.988 \%)$ in the out patients of this hospital. The prevalence of infection of different species of intestinal parasites varied from one another. Prevalence of A. lumbricoides was highest $(21.689 \%)$ and $E$. vermicularis was lowest $(1.008 \%)$, while the remaining four species: (E. histolytica, G. intestinalis, T. trichiura, and A. duodenale) were 10.214, 2.774, 6.052 and $1.513 \%$, respectively (Table 2 ).

Table 2. Prevalence and EPG of each species of gastrointestinal parasites in human

\begin{tabular}{llccccc}
\hline \multirow{3}{*}{ Group } & Parasites & \multicolumn{5}{c}{ Patients of DMCH } \\
\cline { 2 - 6 } & (cyst/ova) & $\begin{array}{c}\text { Total } \\
\text { sample } \\
\text { exam }\end{array}$ & $\begin{array}{c}\text { No. of } \\
\text { infected } \\
\text { samples }\end{array}$ & $\begin{array}{c}\text { Prev. } \\
(\%)\end{array}$ & $\begin{array}{c}\text { No. of } \\
\text { cyst/ova Per } \\
\text { gm }\end{array}$ & $( \pm$ Sd) \\
\hline Protozoa & Entamoeba histolytica & 793 & 81 & 10.214 & 115 & 1.419 \\
& Giardia intestinalis & 793 & 22 & 2.774 & 30 & 1.363 \\
& Overall protozoa & 793 & 103 & 12.988 & 145 & 1.407 \\
Helminth & Ascaris lumbricoides & 793 & 172 & 21.689 & 249 & 1.447 \\
& Trichuris trichiura & 793 & 48 & 6.052 & 55 & 1.145 \\
& Ancylostoma duodenale & 793 & 12 & 1.513 & 26 & 2.166 \\
& Enterobious vermicularis & 793 & 8 & 1.008 & 20 & 2.5 \\
& Overall Helminth & 793 & 240 & 30.264 & 350 & 1.458 \\
\hline
\end{tabular}

Saha and Chowdhury (1981) reported $75 \%$ of children (under 5 years) of Rangpur and Dinajpur districts were found to be suffering from helminth disease. Khaled (1983) recorded $41 \%$ of helminth infections in the soldiers of Bangladesh rifles. Reinthaler et al. (1988) stated that contaminated drinking water is clearly the main source of the high levels of protozoan infection. But in the present study higher rate of parasite infection with helminth suggest that these parasites have highly effective distribution and contact mechanism from one person to another.

The prevalence of E. histolytica, G. intestinalis and A. lumbricoides were higher in females than in males and the prevalence of remaining three species (T. trichiura, A. duodenale and E. vermicularis) were higher in males than in females. Intensity of E. histolytica, G. intestinalis, A. lumbricoides, and A. 
duodenale were higher in males than in females and remaining two species ( $T$. trichiura and E. vermicularis) were higher in females than in males (Table 3).

Table 3. Prevalence of each species (protozoan and helminth) of gastrointestinal parasites in male and female hosts

\begin{tabular}{|c|c|c|c|c|c|c|}
\hline Parasites & Sex & $\begin{array}{c}\text { Total sample } \\
\text { examined }\end{array}$ & $\begin{array}{l}\text { No. of infected } \\
\text { patients }\end{array}$ & Prevalence & $\begin{array}{c}\text { Total cysts / } \\
\text { gm }\end{array}$ & $( \pm \mathrm{Sd})$ \\
\hline & Female & 306 & 37 & 12.091 & 51 & 1.378 \\
\hline \multirow[t]{2}{*}{ Giardia intestinalis } & Male & 487 & 13 & 2.669 & 19 & 1.461 \\
\hline & Female & 307 & 9 & 2.941 & 11 & 1.22 \\
\hline \multirow[t]{2}{*}{ Ascaris lumbricoides } & Male & 487 & 98 & 20.123 & 145 & 1.479 \\
\hline & Female & 306 & 74 & 24.183 & 104 & 1.405 \\
\hline \multirow[t]{2}{*}{ Trichuris trichiura } & Male & 487 & 31 & 6.365 & 33 & 1.06 \\
\hline & Female & 306 & 17 & 5.555 & 22 & 1.29 \\
\hline \multirow[t]{2}{*}{ Ancylostoma duodenale } & Male & 487 & 8 & 1.642 & 19 & 2.375 \\
\hline & Female & 306 & 4 & 1.307 & 17 & 1.75 \\
\hline \multirow[t]{2}{*}{ Enterobius vermicularis } & Male & 487 & 6 & 1.232 & 13 & 2.166 \\
\hline & Female & 306 & 2 & 0.653 & 7 & 3.5 \\
\hline
\end{tabular}

The present results revealed that prevalence of $E$. histolytica was highest $(54.16 \%)$ in 0 - 10 years age group while, prevalence of $G$. intestinalis $(8.33 \%), E$. vermicularis $(4.16 \%)$ and $A$. duodenale $(36.31 \%)$ were highest in 0 - 10 years age group. Prevalence of $A$. lumbricoides was highest (36.31\%) in 51 - 60 years age group and of $T$. trichiura was highest (10.06\%) in 51 - 60 years age group. Prevalence in 0 - 10 years age group and lowest (1.55\%) in 21 - 30 years agegroup (Table 4). Intensity of $E$. histolytica was highest (1.5) in two age groups 41 - 50 and 51 - 60 years and lowest (1.333) in $11-20$ years age group. While, intensity of $G$. intestinalis was highest (2.0) in 0 - 10 and 51 - 60 years age group. Intensity of A. lumbricoides found highest (2.25) in 1 - 10 years age group and that of $T$. trichiura was highest (1.22) in 41-50 years age group. Intensity of $A$. duodenale was highest (2.5) in 51 - 60 years age group and $E$. vermicularis was highest (4.0) in 0 - 10 years age group (Table 4).

Muttalib et al. (1976) studied the intestinal parasites of rural children of Bangladesh. They found highest (63.09\%) prevalence with E. histolytica and $(14.68 \%)$ rate of infection with Giardia in 1-year-old children. In case of $A$. lumbricoides, highest (97.11\%) prevalence in 7 years old children and prevalence of $T$. trichiura was highest (62.59\%) in 11 years old children. Reinthaler et al. (1988) reported highest (12\%) prevalence of E. histolytica in 16 - 30 years age group and prevalence of Giardia was highest $(7.8 \%)$ in $2-5$ years age group. In case of A. lumbricoides, reported highest (65\%) prevalence in $2-5$ years age 
Table 4. Overall prevalence and intensity of different protozoan helminth parasites in different age groups

\begin{tabular}{|c|c|c|c|c|c|c|}
\hline Parasites & $\begin{array}{l}\text { Age groups } \\
\text { (years) }\end{array}$ & $\begin{array}{c}\text { Total } \\
\text { sample } \\
\text { examined }\end{array}$ & $\begin{array}{l}\text { No. of } \\
\text { infected } \\
\text { patients }\end{array}$ & $\begin{array}{c}\text { Prevalence } \\
(\%)\end{array}$ & $\begin{array}{c}\text { Total } \\
\text { cysts/gm }\end{array}$ & $( \pm \mathrm{Sd})$ \\
\hline \multirow{11}{*}{$\begin{array}{l}\text { Giardia } \\
\text { intestinalis }\end{array}$} & $11-20$ & 94 & 15 & 15.957 & 20 & 1.333 \\
\hline & $21-30$ & 129 & 14 & 10.852 & 19 & 1.357 \\
\hline & $31-40$ & 176 & 11 & 6.25 & 15 & 1.363 \\
\hline & $41-50$ & 191 & 12 & 6.282 & 18 & 1.5 \\
\hline & $51-60$ & 179 & 16 & 8.983 & 24 & 1.5 \\
\hline & $0-10$ & 24 & 2 & 8.333 & 4 & 2 \\
\hline & $11-20$ & 94 & 4 & 4.255 & 6 & 1.5 \\
\hline & $21-30$ & 129 & 6 & 4.651 & 8 & 1.333 \\
\hline & $31-40$ & 176 & 5 & 2.840 & 5 & 1 \\
\hline & $41-50$ & 191 & 3 & 1.570 & 3 & 1 \\
\hline & $51-60$ & 179 & 2 & 1.117 & 4 & 2 \\
\hline \multirow{6}{*}{$\begin{array}{l}\text { Ascaris } \\
\text { lumbricoides }\end{array}$} & $0-10$ & 24 & 8 & 3.333 & 18 & 2.25 \\
\hline & $11-20$ & 94 & 5 & 5.319 & 11 & 2.2 \\
\hline & $21-30$ & 129 & 18 & 13.953 & 28 & 1.565 \\
\hline & $31-40$ & 176 & 37 & 21.022 & 52 & 1.405 \\
\hline & $41-50$ & 191 & 39 & 20.418 & 58 & 1.487 \\
\hline & $51-60$ & 179 & 65 & 36.312 & 82 & 1.261 \\
\hline \multirow{2}{*}{$\begin{array}{l}\text { Trichuris } \\
\text { trichiura }\end{array}$} & $0-10$ & 24 & - & - & - & - \\
\hline & $11-20$ & 94 & 5 & 5.319 & 5 & 1 \\
\hline \multirow{3}{*}{$\begin{array}{l}\text { Ancylostoma } \\
\text { duodenale }\end{array}$} & $31-40$ & 176 & 11 & 6.25 & 12 & 1.09 \\
\hline & $41-50$ & 191 & 9 & 4.71 & 11 & 1.222 \\
\hline & $51-60$ & 179 & 18 & 10.05 & 21 & 1.166 \\
\hline \multirow{6}{*}{$\begin{array}{l}\text { Ancylostoma } \\
\text { duodenale }\end{array}$} & $0-10$ & 24 & 2 & 8.333 & 4 & 2 \\
\hline & $11-20$ & 94 & - & - & - & - \\
\hline & $21-30$ & 129 & 2 & 1.550 & 3 & 1.5 \\
\hline & $31-40$ & 176 & 4 & 2.272 & 9 & 2.25 \\
\hline & $41-50$ & 191 & - & - & - & - \\
\hline & $51-60$ & 179 & 4 & 2.234 & 10 & 2.5 \\
\hline \multirow{6}{*}{$\begin{array}{l}\text { Enterobius } \\
\text { vermicularis }\end{array}$} & $0-10$ & 24 & 1 & 4.166 & 4 & 4 \\
\hline & $11-20$ & 94 & - & - & - & - \\
\hline & $21-30$ & 129 & 1 & 0.775 & 3 & 3 \\
\hline & $31-40$ & 176 & 1 & 0.568 & 2 & 2.0 \\
\hline & $41-50$ & 191 & 3 & 1.570 & 8 & 2.666 \\
\hline & $51-60$ & 179 & 2 & 1.117 & 3 & 1.5 \\
\hline
\end{tabular}


group. Similarly, prevalence of T. trichiura was highest $(32.5 \%)$ in 2 - 5 years age-group and highest (25.4\%) prevalence of A. duodenale in 6 - 15 years old children. In a study, de Silva et al. (1997) investigated the morbidity and mortality due to ascariasis, re-estimated and analyzed the sensitivity of global numbers at risk. Brooker et al. (2006) and Bethony et al. (2006) worked on the global epidemiology, ecology and control of soil-transmitted helminth infection: ascariasis, trichuriasis and hookworm.

\section{CONCLUSION}

Like other Asian countries, helminthiasis, anaemia and malnutrition (altogether Nutritional Anemia and Iron Deficiency: NAID) still remain as a major public health problem in Bangladesh. Since health-care seeking behaviour and child caring practices largely depend on the socio-cultural background and may vary across communities. Health problems may also need special attention according to geographical regions, district boundaries and economic-context (Anwar 2002).

\section{LITERATURE CITED}

ALAM, M.S. and KHANUM, H. 2005. Infection of Ascaris lumbricoides and Trichuris trichura among the children of two slum areas in Dhaka city. Bangladesh J. Zool. 33(1): 89- 94.

ANDERSON, R.M. 1986. The population dynamics and epidemiology of intestinal nematode infections. Trans. R. Soc. Trop. Med. Hyg. 80(5): 686-696.

ANWAR, K.S. 2002. Comparative effect of iron and micronutrient supplementation on haemoglobin level and nutritional status of dewormed and non-dewormed children of Sirajganj. pp. 1-51.

BETHONY, J., BROOKER, S., ALBONICO, M., GEIGER, S.M., LOUKAS, A., DIEMART, D. and HOTEZ, P. J. 2006. Soil-transmitted helminth infections: ascariasis, trichuriasis and hookworm. The Lancet 367: 1521-1532.

BLACK, R.E., MERSON, M.H., RAHMAN, A.S.M.M., YUNUS, M., ALIM, A.R.A.M., YOLKIN, R.H. and CURLIN, G.T. 1980. A two years study of bacterial, viral and parasitic agents associated with diarrhoea in rural Bangladesh. J. Infect. Dis. 142(5): 660-646.

BROOKER, S., CLEMENTS, A. C. and BUNDY D. A. 2006. Global epidemiology, ecology and control of soil-helminth infections. Adv. Parasitol. 62: 221-261.

CHEesbrough, M. 1987. Medical Laboratory Manual for Tropical Countries. Blackworth Co. Publishers. 570 pp.

CHOWDHURY, M.R. 1978. Intestinal parasitic infections in privileged class of Dhaka population. Bangladesh Armed Forces Medical Journal 4(1): 5-12.

DE SILVA, N. R., CHAN, M. S. and BUNDY, D. A. 1997. Morbidity and mortality due to ascariasis: re-estimation and sensitivity analysis of global numbers at risk. Trop. Med. Int. Health 2: 519-528.

GILGEN, D., C.G.N., MASCIE-TAYLOR and L. ROSETTA 2001. Intestinal helminth infections, anaemia and labour productivity of female tea puckers in Bangladesh. Tropical Medicine International Health 6(6): 449-457. 
HOSSAIN, M.M., LJUNGSTROM, I., GLASS, R.I., LUNDIN, L., STOOLAN, B.J., and HULDT, G. 1983. Amoebiasis and giardiasis in Bangladesh. Parasitological and serological studies. Trans. R. Soc. Trop. Med. Hyg. 77(4): 552-554.

ISLAM, A., STOOL, B.J., LJUNGSTROM, I., BISWAS, J., NAZRUL, H., and HULDT, G. 1983. Giardia lamblia infections in a cohort of Bangladeshi mothers and infants followed for one year. $J$. Pediatr. 103: 996-1000.

KHALED, G.A. 1983. Incidence of intestinal parasitic infection in Bangladesh rifiels. Bangladesh Armed Forces Medical Journal 7(1): 29-31.

KHANUM, H., ISLAM, N. M. and DHAR, T. 1997. Prevalence of Ascaris lumbricoides and Trichuris trichiura among the children of four slum areas of Dhaka city. Univ. J. Zool. Rajshahi Univ. 16: 89-94.

KHANUM, H., CHOWDHURY, S. and SULTANA, S. 1998. Prevalence of Giardia intestinalis among the children of rural areas of Bangladesh. Bangladesh J. Zool. 26(2): 85-89.

KHANUM, H., CHAWDHURY, S. and BHUIYAN, J. Z. 1999. Infestation of three intestinal worms in children of three selected rural areas, Bangladesh. Pakistan J. Zool. 31(4): 391-396.

KHANUM, H., CHAWDHURY, S. and SEN, A. 2001. Comparative efficacy of albendazole, mebendazole and neem leaf extract in the treatment against human intestinal helminthes. Trans. Zool. Soci. East India 5(1): 65-69.

KHANUM, H. and ALAM, M.S. 2005. Infection of Ascaris lumbricoides and Trichuris trichiura among the children of two slum area in Dhaka city. Bangladesh J. Zool. 33(1): 89-95.

KHANUM, H., SULTANA, Y. and HAQUE, R. 2005. Serological prevalence of Entamoeba histolytica among the urban children of Bangladesh. Bangladesh J. Zool. 32(2): 207-212.

LIU, L., JOHNSON, H.L., COUSENS, S., PERIN, J., SCOTT, S., LAWN, J.E., RUDAN, I., CAMPBELL, H., CIBULSKIS, R., LI, M., MATHERS, C. and BLACK, R.E. 2010. Global, regional, and national causes of child mortality: an updated systematic analysis for 2010 with time trends since 2000. The Lancet 379(9832): 2151-2161.

MUTTALIB, M.A., ISLAM, N. and ISLAM, S. 1976. Prevalence of intestinal parasites in rural children of Bangladesh. Bangladesh Med. J. 4(1): 11-26.

REINTHALER, F.F., MASCHER, F., KLEM, G. and SIXL, W. 1988. A survey of gastrointestinal parasites in Ogun State, southwest Nigeria. Annals of Tropical Medicine and Parasitology 82: 181-184.

SAHA, B. and CHOWDHURY, A.B. 1981. Helminthic infection in under five children in Rangpur and Dinajpur districts. Bangladesh Med. J. 16(2): 7-11.

SHAKUR, M.S. and EHSAN, M.A. 1993. Intestinal Parasites: A frequent association and contributing factor of loose motion in malnourished children. Bangladesh Journal of Child Health 17(1): 10-13.

STEPHENSON, L.S. 1987. Impact of helminth infections on human nutrition. Parasitology Today. Taylor and Francis. London. 223 pp.

WALKER, C.L.F., ARYEE, M.J., BOSCHI-PINTO, C. and R.E. BLACK. 2012. Estimating diarrhea mortality among young children in low and middle income countries. PloS One 7(1): 29151.

WALSH, J.A. 1986. Problems in recognition and diagnosis of amoebiasis: estimation of the global magnitude of morbidity and mortality. Rev. Infect. Dis. 8: 228-238.

WHO (WORLD HEALTH ORGANIZATION). 1987. Prevention and control of intestinal parasite infection. Report of a WHO Expert committee. WHO Tech. Rep. Ser. 749: 1-86. 
WHO (WORLD HEALTH ORGANIZATION). 1997. Amoebiasis. WHO Weekly Epidemiol. Rec. 72: 97-100.

WHO (WORLD HEALTH ORGANIZATION). 2005. Dewaorming for health and development. Report of the global meeting of the partners for parasite control. Geneva: World Health Organization. pp. 25-26.

(Manuscript received on 27 March, 2016; revised on 25 June, 2016) 